\title{
La construcción de la masculinidad a través de la socialización de lo biológico y la biologización de lo social en el manual de seducción «Apocalipsex»
}

\author{
The masculinity construction through socialization of \\ the biological and biologicization of the social in the \\ «Apocalipsex» seduction manual
}

\section{RESUMEN}

El modelo de masculinidad deseable asociado al fenómeno de la seducción ha sido constituido de forma generalizada en base a presupuestos evolucionistas y biologicistas. Desde una perspectiva socio-construccionista y de género analizamos el proceso de construcción de la masculinidad que se reproduce en el manual de seducción «Apocalipsex: los 10 mandamientos de la seducción», mediante la herramienta analítica Grounded Theory. Del análisis concluimos que este manual, respaldándose en estudios de corte biologicista y evolucionista, construye y reproduce como deseable un modelo de masculinidad cuyas pautas de seducción tienen lugar a partir de la virilidad, la actividad sexual, el poder, la dominación, la autoridad, la actividad, la agencia, el riesgo, la presencia, la protección, la insensibilidad y la racionalidad. Asimismo, se trata de forma despectiva a los hombres que no encajan en este modelo, y a las mujeres se las reduce y presenta como objetos sexualizados que representan y dotan de masculinidad a los hombres.

Palabras clave: Seducción; Masculinidades; Feminismo; Virilidad; Maestros de la seducción.

\begin{abstract}
The desired masculinity model associated with seduction phenomenon has been constituted through the board based on evolutionist and biological assumptions. We have analysed the construction process of masculinity, from a social constructionist and gender perspective, reproduced in the seduction manual «Apocalipsex: los 10 mandamientos de la seducción», using the analytic method of Grounded Theory. From the analysis we concluded that the seduction manual, with the support of evolutionist and biological studies, constructs and reproduces a desirable model of masculinity whose seduction guidelines take place from virility, sexual activity, power, domination, authority, activity, agency, risk, presence, protection, insensitivity and rationality. Moreover, the men who do not adjust in this model are treated pejoratively, and women are minimized and appear as sexual objects that represent and provide masculinity to men.
\end{abstract}

Keywords: Seduction; Masculinities; Feminism; Virility; Pick-up artists (PUA).

\section{SUMARIO}

1.- Introducción. 2.- Metodología. 3.- Resultados y discusión. 3a.-Sexualidad y virilidad. 3b.- Poder y Dominación. 3c.- Actividad y agencia. 3d.- Riesgo y Virilidad. 3e.- Protección y Presencia. 3f.- Racionalidad e Insensibilidad. 4.- Conclusiones. 5.- Bibliografía. 


\section{1.-Introducción}

Términos como el que acuñaron los etólogos Frank A. Beach y Lisbeth Jordan (1956) en sus estudios con ratas -el efecto Coolidge, o el de inversión parental de Trivers (1972), entre otros- han valido para construir y reproducir el discurso biologicista como variable explicativa en lo que a la sexualidad de hombres y mujeres respecta. Estos autores hacen hincapié en la existencia de una naturaleza sexual del hombre que conlleva la necesidad de mantener relaciones sexuales variadas y abundantes con otras mujeres. Los autores biologicistas defienden la existencia de ciertas disposiciones programadas en nuestros genes respecto al galanteo. Defienden la existencia de algunos movimientos corporales similares de flirteo en varones y mujeres en varias culturas y grupos estudiados (Morris, 1980; Lorenz, 1986 y Eibl-Eibsfeldt, 1993). Desde una perspectiva antropológica, el comportamiento corporal de galanteo presenta variaciones en diferentes culturas, $\mathrm{y}$, por tanto, se considera un evento particular dependiente de la cultura y no algo universal y generalizado como se defiende desde los enfoques biologicistas (Birdwhistell, Desmonts y Ramió, 1979; Scheflen y Scheflen, 1976 y Fisher, 1992). Robert Stoller (1994) sostiene que, aun considerando la tendencia sexual de los seres humanos como un impulso, es preciso señalar que esta faceta que llamamos «conducta sexual» es el fruto de un aprendizaje que comienza con la temprana socialización del individuo y queda reforzado por las experiencias de adulto. Asimismo, Carlos Yela (2000) en sus trabajos sobre el amor desde la psicología social hace un recorrido a través de los distintos autores que han estudiado las diferencias interculturales sobre el fenómeno amoroso. Encuentra que los cánones sexuales, las características que nos atraen, las pautas de seducción y noviazgo, los estilos amorosos, los criterios de elección de pareja y los rituales de vínculo varían de una cultura a otra, en función de los roles, normas sociales, valores y pautas socio-culturales vigentes en cada una, y rechaza así las teorías que sostienen que estas pautas vienen determinadas genéticamente.

Estudiando las relaciones de poder y los procesos de socialización en los adolescentes, Elboj et al. (2009) encuentran que, salvo alguna excepción, se siguen reproduciendo los patrones patriarcales, donde los chicos líderes que ejercen dominación sobre sus compañeros y las chicas consideradas como las más guapas siguen siendo los objetivos a conseguir. Amurrio et al (2010), sostienen que la dominación masculina presente en nuestra sociedad bajo el proceso de socialización diferencial es introducida en la estructura de personalidad de hombres y mujeres en la que chicos y chicas han interiorizado unas pautas relacionales de género en la esfera afectiva que explican no sólo la agresividad violenta de muchos varones, sino también el amor de muchas mujeres hacia estos varones terribles. Asimismo, observan que los jóvenes plantean una relación entre iguales, pero en su mayoría concurren características propias de una relación dependiente, en la que las mujeres jóvenes quieren ser protegidas y que les aporten seguridad y en la que los hombres jóvenes prefieren a mujeres atractivas y guapas para mantener relaciones sexuales. Padrós, Aubert y Melgar, (2010) encuentran que muchas chicas admiten sentirse 
atraídas por aquellos chicos que menosprecian a las mujeres y cuyas características se asocian al modelo tradicional de masculinidad, desvalorizándose los chicos que no siguen esta dinámica. Bajo la teoría de la socialización diferencial, Padrós, Aubert y Melgar (2010) han encontrado que aquellos que no cumplen con los mandatos de la masculinidad tradicional, chicos sensibles o solidarios, se consideran «sosos» y poco atractivos, son los amigos y no los chicos de los que quieren enamorarse. En esta misma línea, Ferrer y Bosch (2013), señalan que durante todo el proceso de socialización son muchos los mensajes recibidos por los niños y niñas, adolescentes y jóvenes en relación con los roles que deben asumir en las relaciones afectivas, lo que cada uno debe dar y espera recibir, como variables explicativas a estos fenómenos. De este modo, los agentes socializadores posibilitan la construcción, mantenimiento y reproducción de discursos sobre la seducción y las prácticas sexoafectivas.

Hall y Canterberry (2011) analizaron las estrategias de cortejo asertivas de varones heterosexuales defendidas en el libro The Game: Penetrating the Secret Society of Pick-up Artist (Strauss, 2005) (En español salió a la venta como «El método»). Concluyeron que estas estrategias orientan sobre el comportamiento que deben adoptar los varones para seducir a las mujeres. Estrategias cargadas de ideologías machistas, en las que a las mujeres se las veía como objetos que se pueden conquistar y manipular a través de determinadas pautas comportamentales esperadas. Gloria Rincón (2014) en su estudio sobre los roles de seducción entre los jóvenes de Bogotá encontró que a las mujeres se les ha asignado un rol pasivo en las interacciones de seducción, y tienen que permanecer sumisas a la espera de ser cortejadas por el hombre, y procurar no mostrar interés para iniciar la interacción. Esto coincide con lo observado por Sánchez-Sicilia y Cubells (2018), quienes recogen cómo en el proceso de conquista amoroso-sexual el hombre es mostrado como agente activo en la búsqueda sexual o de pareja, mientras la mujer es mostrada como objetivo de conquista en las prácticas románticas y un objeto de consumo en las prácticas líquidas. La seducción no solamente puede usarse como una forma de expresión del deseo, sino también como una promesa falsa, una manipulación para conseguir lo que la otra persona no haría de buenas a primeras (Royo, 2018). De este modo se perpetúa una visión de la masculinidad como algo que se obtiene al lograr acceso sexual al cuerpo de las mujeres, mediante un proceso de seducción que se fundamenta en desequilibrios de poder, donde necesidades y deseos masculinos son por principio priorizados por delante de los de las mujeres, quienes son presentadas como "problemas técnicos a resolver» (O'Neill, 2018). Katie Baker (2013) muestra que los hombres que participan en comunidades de seducción consideran a las mujeres como un grupo homogéneo pasivo ante el cual «un rechazo no es una opción», insistiendo y adaptando las estrategias si fuera necesario con tal de conseguir mantener relaciones sexuales con ellas.

Trabajos recientes muestran cómo las comunidades de seducción emplean los conceptos de la psicología evolutiva y la diferenciación sexual como marco teórico a través de los cuales justifican y legitiman los principios y pautas que promueven, mostrando a hombres y mujeres como seres programados, con funciones y 
comportamientos genéticamente diferenciados (Baker, 2013; O’Neill 2018; Van Valkenburgh, 2018)

\section{2.-Metodología}

En tanto que nuestro estudio se enmarca en la perspectiva socio construccionista, la metodología a utilizar es de corte cualitativo. Con ella, a través de la interpretación, pretendemos comprender la naturaleza de los procesos sociales más que explicarla o predecirla (Iñiguez, 2008). Partimos de la idea de que al interaccionar y comunicarnos unos con otros construimos el mundo en el que vivimos (Gergen y Gergen, 2011). El construccionismo entiende el conocimiento como el producto de comunidades determinadas, guiadas por supuestos, creencias y valores concretos (Gergen, 2007). En este trabajo partimos de una premisa común: del mismo modo que «no se nace mujer, se llega a serlo» (De Beauvoir, 1949), no se nace hombre, se llega a serlo. De este modo, comprendemos el fenómeno de la masculinidad como un constructo basado en normas sociales, culturales y contextuales, que se sustenta en unas prácticas y roles diferenciados, que organizan y califican una masculinidad como modelo deseable y hegemónico, en detrimento de otros modelos alternativos.

Nuestro trabajo se ha centrado en el análisis del manual de seducción «Apocalypsex: los diez mandamientos de la seducción» (Mario Luna, 2015)2.

El análisis del material se ha llevado a cabo mediante la Grounded Theory (GT) de Glaser y Strauss (1967), la cual nos permite generar categorías de forma inductiva mediante una comparación simultánea de todos los incidentes observados, explorando las relaciones de unos con otros e integrándolos en una teoría coherente. La GT altera el orden habitual de la revisión de la literatura y la recolección de los datos. La GT busca adaptar los descubrimientos previos a las características específicas del fenómeno en estudio (Hirschman \& Thompson, 1997). La GT nos permite explicar el fenómeno que estudiamos apoyándonos en los datos recogidos e interpretando el fenómeno a través de explicaciones teóricas de carácter formal. De este modo, a la hora de desarrollar las categorías, el conjunto de signos y reglas que nos permiten formular y comprender el discurso, tendremos en cuenta las que emergen de los códigos «in vivo», que se generan del lenguaje sustantivo, de datos brutos(incidentes), y las que emergen de los «constructos sociológicos», códigos formulados desde el conocimiento sociológico (Murillo et al., 2011).

Tras analizar el material completo, hemos recogido un total de 17 páginas de incidentes (de las 208 que componen el material), entendiendo por incidente cada parte de la unidad de muestreo que puede ser considerada como analizable separadamente. Es aquella porción que el investigador aísla y separa por aparecer en este uno de los símbolos, palabras clave o temas que considera trascendentales para el análisis (Murillo et al., 2011).

2 Dicho libro ha centrado nuestro análisis por su actualidad, su alcance, por encontrarse actualmente a la venta en su quinta edición, por ser la guía definitiva de la trilogía que componen SexCrack (Luna, 2013) y SexCode (Luna, 2009) y por encontrarse en la categoría «los más vendidos en guías sexuales» de Amazon España -junto a SexCrack- (Amazon.es, 2020). 
El libro que aquí analizamos se encuentra actualmente a la venta en su quinta edición, disponible para cualquier persona que quisiese adquirirlo. Asimismo, el artículo 32 del Real Decreto Legislativo 1/1996, de 12 de abril, considera en lo que a nuestro caso se refiere:

Lícita la inclusión en una obra propia de fragmentos de otras ajenas de naturaleza escrita, sonora o audiovisual [...] siempre que se trate de obras ya divulgadas y su inclusión se realice a título de cita o para su análisis, comentario o juicio crítico. Tal utilización sólo podrá realizarse con fines docentes o de investigación [...]

Una vez analizado el material y reducido a los incidentes a analizar, comenzamos el mismo proceso con el manual Sexcrack (Luna, 2013). A medida que avanzábamos en el análisis, no emergía información nueva o adicional, y, por lo tanto, aplicando el criterio de saturación teórica, dimos por resuelta la categoría principal y finalizado el proceso de recogida de incidentes, y nos centramos en los que habían emergido del manual «Apocalypsex: los diez mandamientos de la seducción» (Luna, 2015).

Mediante el método comparativo constante hemos cotejado y codificado incidentes. Posteriormente, de las codificaciones resultantes han emergido diversas categorías, y hemos integrado los respectivos incidentes en ellas. Una vez que teníamos las categorías bien definidas, a partir de los códigos in vivo y apoyados en los constructos sociológicos, conceptualizamos las teorías que emergen del material. De forma inductiva emergió la categoría central que explica y da sentido a todos los datos y sus relaciones y, por tanto, explica la mayor variabilidad del patrón de comportamiento social que orienta el estudio. Una vez localizada la categoría central que orienta el proceso de investigación, presentaremos, a modo de ejes temáticos, familias de incidentes codificados que tienen relación entre sí y se inscriben en una categoría concreta, sustentada y explicada por la categoría central. Presentamos los extractos literales del manual, los cuales se presentan en cursiva, asimismo, las negritas fueron añadidas por el autor de este artículo para destacar aquellas expresiones claves para el análisis.

\section{3.-Resultados y discusión}

Justificándose en lo innato, lo biológico, lo genético ... el autor del material que analizamos presenta a mujeres y hombres como polos de un dualismo diferenciado. De este modo y, al igual que recoge Baker, (2013), O'Neill (2018) y Van Valkenburgh, (2018) sobre las comunidades de seducción, el autor del manual emplea los conceptos de la psicología evolutiva y la diferenciación sexual como marco teórico, justificando y legitimando las pautas que se muestran en el manual, considerando a hombres y mujeres como seres programados, con funciones y comportamientos genéticamente diferenciados. Esta idea -reforzada por autores evolucionistas y biologicistas- emerge de forma transversal a lo largo de todo el material a modo de marco teórico, rechazando e invisibilizando cualquier otra perspectiva, enfoque o variable explicativa que aborde el fenómeno objeto de estudio. Al contrario de lo que se enarbola en este manual, la historia de los hombres y las mujeres nos ha mostrado que no existe una naturaleza humana fija e inmutable, pero sí un 
carácter que se construye a través de la estructura social y la conciencia colectiva (De Miguel, 2015). Antes de presentar los extractos del material nos gustaría traer a colación las palabras del sociólogo Pierre Bourdieu (2000):

Las apariencias biológicas y los efectos indudablemente reales que ha producido, en los cuerpos y en las mentes, un prolongado trabajo colectivo de socialización de lo biológico y de biologización de lo social se conjugan para invertir la relación entre las causas y los efectos y legitimar una relación de dominación inscribiéndola en una naturaleza biológica que es en sí misma una construcción social (Bourdieu, 2000)

Aquello que hace que tú te vuelvas loca de deseo por un hombre es, por lo general, distinto de aquello que hace que tú le pongas a él (Luna, 2015, p. 32) Al igual que a ti, (a las mujeres) sus genes la han programado para responder a ciertas cosas. Cuando vivíamos en cavernas e investigábamos el fuego, a ellas les perdía el líder de su tribu [...] A día de hoy, aunque el mundo ha cambiado mucho, sus instintos ancestrales no lo han hecho (Luna, 2015, p.34) [...]Desde una perspectiva evolucionista, esto tiene mucho sentido. Pues cuando vivíamos en tribus, a las mujeres les iba la calidad de su descendencia en ello (Luna, 2015, p. 58). Esa es, al menos, la tesis sobre la que se sostiene todo mi trabajo. Por suerte para mí, no estoy solo en esto. Gracias a científicos como Richard Dawkings, David Buss, Steven Pinker, Matt Ridley, Geoffrey Miller o Robin Baker, la psicología evolucionista que considera la esencia de nuestro comportamiento sexual está preprogramado genéticamente y se puede explicar desde una óptica evolucionista- ha pasado a ser el fundamento de la psicología moderna. (Luna, 2015, p.34)

\section{a. Sexualidad y Virilidad}

Las sociedades producen relatos que naturalizan instituciones sociales, como la creencia de que existe una naturaleza sexual masculina que se manifiesta como un impulso irrefrenable (Cobo, 2017). De esta manera, la cultura se ha construido sobre la férrea idea de que los hombres tienen más apetito y más potencia sexual que las mujeres (Royo, 2018), un apetito considerado desmesurado e imprevisible (Marqués y Osborne, 2011). De este modo, se desprende la imagen de la sexualidad masculina construida desde una posición hegemónica de privilegio social y, por tanto, que posibilita el libre disfrute de la sexualidad en un ejercicio de promiscuidad históricamente negado a las mujeres (Sambade, 2017). Asimismo, supone una exigencia moral y un sexismo que exige a los hombres virilidad y heterosexualidad (López-Sáez, García-Dauder y Montero, 2019). El autor de la guía presenta un modelo de hombre deseable, el «hombre Ganador», aquel que se identifica y es identificado según las tesis evolucionistas que sostienen la necesidad biológica de los hombres de mantener relaciones sexuales con muchas y variadas mujeres. Pensamiento que reduce y valora a los hombres «machos alfa» a su papel dominante sexual. Elisabeth Badinter (1992) en sus estudios sobre la identidad masculina analiza de qué manera el hombre, para alcanzar su masculinidad tiene que convencerse y convencer a los demás de tres cosas: que no es una mujer, que no es un bebé y que no es homosexual. El hombre dedica una gran parte de su tiempo 
en demostrar que es un «verdadero hombre», la masculinidad es, pues, algo que está en constante (auto) evaluación, y que como muestran Vicent Marqués y Raquel Osborne (1991), la vivencia de la sexualidad en los hombres se ve condicionada a una forma de confirmación de la masculinidad. Del mismo modo que muestra Ismael Ocampo (2019), las nociones de lo que significa ser hombre se articulan con el carácter violento de la masculinidad, que se relaciona con la necesidad constante de demostración de la misma, por medio de la violencia competitiva.

La masculinidad se sigue aprendiendo en el patio del colegio como negación de lo que es ser una niña y en la etapa adolescente como dominio y, por tanto, quién accede a más cuerpos de chicas se le puntúa positivamente (De Miguel, 2015). De este modo, La identidad masculina se construye a través de los paradigmas de la cantidad: el tamaño del pene, el número de parejas sexuales, la cantidad de prácticas sexuales y, de este modo y como recoge Adriana Royo (2018) sobre los machos alfa, «Su autoestima dependerá de sus méritos, no se valorarán como personas sino como datos y necesitarán desarrollar un ego tan grande como sus éxitos». Parafraseando a Kate Millet (1970), las mujeres y las relaciones sexuales que mantengan con ellas serían el espejo en el que se miran estos hombres para construir su identidad masculina y por tanto su autoestima. Las mujeres quedan desprovistas de cualquier característica que las defina como persona, se las aísla del todo y se las identifica a partir de sus partes o funciones sexuales, reduciéndolas a instrumentos que logran representar al sujeto dominado (Lee Bartky, 1990). Así se perpetúa una visión de la masculinidad como algo que se logra tras la consecución del acceso sexual al cuerpo de las mujeres, mediante un proceso de seducción que se fundamenta en desequilibrios de poder, donde se priorizan necesidades y deseos de los hombres en detrimento de los de las mujeres, quienes son presentadas como «problemas técnicos a resolver» $\left(\mathrm{O}^{\prime} \mathrm{Neill}, 2018\right)$ :

Mi relación con las mujeres seguía siendo constante pesadilla. A veces pasaba meses, o años, sin acostarme con nadie. Una vida de fracasos [...] al menos en lo que respecta a las mujeres [...] El mundo entero se mofaba de mí (Luna, 2015, p. 21). A fin de cuentas, un Ganador se conquista a sí mismo. Antes de poseer el mundo y sus mujeres, he aprendido a ser dueño de sus propias emociones (Luna, 2015, p.37) El mensaje es que disfrutes del momento. Aun cuando ella no lo hiciese, al pasártelo tú bien consigues activar su Punto GG (Ganador ganado) (Luna, 2015, p. 38)

Si estás con una chica que te atrae, pero no tienes relaciones sexuales con ella, no vas a hacer nada que implique algún tipo de esfuerzo, tiempo o inversión por tu parte. (Luna, 2015, p.148) [...] Que entienda que tengo pilila y suficientes opciones como para no perder mi tiempo con situaciones que no me aporten nada. (Luna, 2015, p.149) Lo mejor cuando Paquita no cumple con su parte del trato es tener el teléfono de Pepita suculento y humeante (Luna, 2015, p.165) [...] Si ella no te da lo que hace falta para retenerte a su lado como hombre, eres totalmente libre de seguir experimentando con otras mujeres hasta que des con aquella que sepa completarte (Luna, 2015, p.200) Negando tu condición de criatura sexual o la de ellas, cometes una enorme injusticia. Recuerda que un Ganador jamás renuncia a su naturaleza sexual (Luna, 2015, p.146) 
En las expresiones anteriores se pone de manifiesto la referencia al sexo como a una divisa (Perry, 2017) donde lo primordial que podría ofrecer una de las mujeres a las que hace referencia esta guía son las relaciones sexuales y una reafirmación de la masculinidad de estos hombres. De este modo, las mujeres son objetualizadas y deshumanizadas simbólica y culturalmente para la satisfacción sexual de los varones y la confirmación de su masculinidad (Sambade, 2017). Asimismo, dadas las similitudes observadas, nos gustaría traer a colación el trabajo de Ana de Miguel (2015) en el que recoge como la práctica de la prostitución refuerza la concepción de las chicas/mujeres como cuerpos de los que es normal disponer, que no suscitan el interés de preguntarse cómo o por qué están ahí; cuerpos femeninos como cuerpos subalternos -en los cuales se inscriben las definiciones patriarcales- sobrecargados de sexualidad para satisfacer la mirada del hombre heterosexual (Cobo, 2017).

Bourdieu (2000) recoge de qué manera el acto sexual es concebido por el hombre como una forma de dominación, de apropiación, de posesión. Los chicos son propensos a compartir sus hazañas sexuales, concebidas como un acto agresivo y sobre todo físico de conquista, orientado a la penetración y el orgasmo. A lo largo del material, el autor dedica un espacio a los «hombres no ganadores», a los no machos alfa. En el material se aprecian maneras de denominarlos cargados de desprecio por no reproducir aquellas características que definen y dan identidad a la masculinidad que aquí se presenta como deseable... «Un Ganador jamás renuncia a su naturaleza sexual» (Luna, 2015, p.146):

Cada vez que inviertes tiempo, dinero o energía en una relación estancada, les estás telegrafiando a las mujeres que: o no eres un ganador, y lo haces por necesidad; o no tienes pilila, y lo haces por eso. Cada vez que caes en una situación de este tipo, estás admitiendo que no tienes pilila [...] Y cada vez que aceptas este marco, ¿sabes lo que ocurre? Que, en efecto, ella te pierde el respeto y te ve con menos pilila. (Luna, 2015, p. 146) [...] a veces me he saltado este principio, cada vez que lo hago caigo en la trampa del seductor pelele. Me convierto en uno de esos hombres sin pilila y empiezo a jugar como ella quiere o de algún otro modo (Luna, 2015, p.148). ¿Te gustaría descubrir todo lo que NO debes hacer para evitar que te encasillen como un hombre de poca valía? (Luna, 2015, p. 150)

Quien es un hombre y pretende encarnar una masculinidad hegemónica deberá, de diferentes maneras en diferentes contextos, demostrar su posición como hombre y luchar para que no le sea arrebatada (Azpiazu, 2017). En este caso, la posición como hombre se construye en base al acto sexual. Las actitudes y conductas consideradas poco viriles son, así, sancionadas usando calificativos que degradan y cuestionan la masculinidad (Guasch, 2008); es sancionado aquel hombre «sin pilila» que no encarna una masculinidad para el autor deseable. El estudio de Padrós, Aubert y Melgar (2010) muestra cómo en las prácticas de seducción se desvaloriza a los chicos que no siguen las dinámicas de la masculinidad tradicional. Cuando se refiere al «hombre no ganador» se emplea de forma intencionada y en repetidas ocasiones el término «pilila» con la intención de infantilizarlo, rebajarlo a niño, a bebé (Badinter, 1992) y no identificarlo como hombre. Cuando se refiere al hombre 
ganador, emplea mayoritariamente el término «polla; Y jamás, jamás vas a negar que tienes polla» (Luna, 2015, p. 148). El pene concentra todas las fantasías colectivas de la fuerza fecundadora (Bourdieu, 2000, p. 23) y simboliza un derecho histórico e inalienable al poder, el respeto y el orgullo (Buchbinder, 2013). Dentro de esta construcción, la masculinidad se mide de acuerdo con la multiplicidad de relaciones heterosexuales. La satisfacción está centrada en los genitales y en la penetración. Se caracteriza también por la homofobia y el rechazo a cualquier feminización de sus conductas (Kaufman, 1994 y Figueroa-Perea 1998).

\section{b. Poder y Dominación}

El poder social para los hombres es la fuente de su poder y privilegios (Kaufman, 1994) la capacidad de ejercer control, de imponer definiciones e intereses, sobre los asuntos ajenos, comunes y también los propios (Emakunde, 2008). El poder confiere la capacidad de dominar y no ser dominado; la masculinidad hegemónica configura unas prácticas de género que dan sentido a la legitimidad del patriarcado, que garanticen la posición dominante en los hombres y la subordinación en las mujeres (Romero Díaz y Abril Morales, 2011). Si consideramos la masculinidad como un deseo permanente de tener el control de la situación, entonces perder dicho control es síntoma de una masculinidad dañada, de una pérdida de masculinidad (Kimmel, 2017). Para la virilidad es fundamental aparentar poder y es interesante observar cómo los hombres usan sus atributos para llamar la atención femenina (Royo, 2018) $\mathrm{y}$, por tanto, instalarse en una situación favorable de poder, de reafirmación de su identidad masculina, y satisfacer así deseos de dominio y ser objeto de atención (De Miguel, 2015). Esto deriva en una necesidad de dominar, de impresionar, tan fundamental para la masculinidad, que siempre hallará una manera de expresarse (Perry, 2017), que en este caso se manifiesta a través de expresiones como: «la mirada, el insinuarte, preguntar, acusar, culpar, desaprobar, despreciar, premiar, sonreír, burlarte, animar, atacar, defenderte o acariciar...»

Dota tu presencia de autoridad y poder (tono, gestos, ropa etc.) Esta vez usa tu presencia para infundir respeto, autoridad y poder. Domina en lenguaje de la mirada. A menudo una mirada basta. Los Ganadores lo saben. Con la mirada puedes dominar, insinuarte, preguntar, acusar, culpar, desaprobar, despreciar, premiar, sonreír, burlarte, animar, atacar, defenderte o acariciar. Puedes hacer que una chica no pare de pensar en ti, se ponga roja o incluso moje su ropa interior (Luna, 2015, p.61)

Porque ¿cuál es la forma más rápida de regalarle tu poder a alguien o algo? Darle control sobre tus emociones [...] Por eso, nada de lo que ellas hagan debe otorgarles dicho dominio [...] Tener poder sobre las emociones de alguien que no es su pareja también les indica otra cosa: que dicho hombre carece de opciones con otras mujeres. En la mayoría de los mamíferos, los machos dominantes son los que adoptan posturas más cómodas y ocupan más espacio (Luna, 2015, p.60). A nadie le gusta llegar lejos para que le arrebaten el premio justo en el último momento ¿verdad? (Luna, 2015, p.197) [...] Y por supuesto, convéncete de que, en el fondo, ella lo desea todavía más que tú. Al hacerlo, entrará en vigor la ley de la realidad dominante. A veces te comportas como un troglodita consentido porque percibes que, en su fuero más interno, ella desea que la secuestres. Anhela en ti al 
salvaje que la cargaría sobre sus hombros y sin preguntar a nadie, la arrancaría de su cueva para fundar una familia (Luna, 2015, p.81)

\section{c. Actividad y Agencia}

Siguiendo en la línea del poder y la dominación/subordinación; la actividad/ pasividad supone otro par del dualismo jerarquizado masculino/femenino (Olsen, 2000). Parafraseando a Elisabeth Badinter (1992), la socialización diferencial de género condiciona a los hombres para que se conviertan en «máquinas sexuales»; hiperpotentes e hiperactivos, más vacíos de

aquellas emociones consideradas socialmente como «femeninas». Las mujeres son mostradas en actitud pasiva y sumisa, mientras que los varones aparecen en actitudes activas y dominantes (Subirats, 2013) y que, por ende, la mujer se convierte en un objeto de conquista en las prácticas románticas y de consumo en las prácticas líquidas (Sánchez-Sicilia y Cubells, 2018). El autor del material que aquí analizamos emplea expresiones diferenciadas para referirse por un lado a los hombres que encarnan una masculinidad deseable y por otro a las mujeres. Asimismo, legitima una relación de dominación inscribiéndola en una naturaleza biológica que es en sí misma una construcción social (Bourdieu, 2000)

Si adoptas el disfraz de borreguito es muy posible que tan solo logres potenciar tu naturaleza de borreguito y jamás llegues a convertirte en un depredador [...] Recuerda que no ser un lobo es una limitación más (Luna, 2015, p. 118) Recuerda, eres un lobo. Enséñale los dientes a la oveja. Si la oveja no se aparta, te la puedes comer ¿te lo repito? Cómetela o espántala. (Luna, 2015, p.119) [...]Todo apunta a que eres el ganador (Luna, 2015, p.141) [...] ¿No te ha llamado jamás la atención cómo muchas de ellas parecen sentirse sexualmente atraídas por hombres que visten como auténticos ex presidiarios? ¿Qué es lo que tiene la estética del chico malo? De nuevo te recordaré sus instintos ancestrales y su predilección por los buenos cazadores y guerreros (Luna, 2015, p. 64)

Te vas a dejar de cacerías y te vas a convertir en un agricultor. Cuando puedas recolectar lo harás. Cuando no, te dedicaras a sembrar [...] porque en la vida los ganadores no cazan. Cultivan [...] Siempre que puedas vas a escalar. Y cuando no puedas escalar, te dedicaras a sembrar y a cuidar tu huerto (Luna, 2015, p. 111) [...]En su grado óptimo de madurez, tu obligación es recolectarla (Luna, 2015, p.117)

Por una parte, muestra al «hombre ganador» como un «lobo, un depredador» animal, activo, impulsivo, impaciente -y por tanto como un ser emocional- en la consecución de su objetivo, un objetivo que como hemos visto con anterioridad les define, les identifica. En palabras de Kate Millet (1970), la hembra es el espejo en el que se mira el macho, haciendo referencia a la importancia que tiene para la construcción de la identidad de los hombres el acceso al cuerpo de las mujeres. Por otra parte, Luna (2015) presenta al hombre como un «agricultor», un ser de nuevo activo, pero esta vez calculador, sensato, paciente, racional-y, por tanto, como ser no emocional-... cuyo objetivo sigue siendo el anteriormente recogido. De este modo, observamos una contradicción recurrente en las pautas dadas por el autor al referirse a la sexualidad masculina que glorifica como incontrolable y 
predadora: «Aprende a morder sin miedo y a desatar tu instinto animal. Hazlo como sea. Paga el precio» (Luna, 2015, p. 118) -justificada por los postulados biológicos que el autor emplea- y, al mismo tiempo, enarbolar el carácter racional y calculado de la masculinidad: «La mayoría de los hombres presos de la lógica (...) prestamos demasiada atención a los razonamientos» (...) (Luna, 2015, p.103). De esta manera, se pone de manifiesto el carácter artificial de las categorías adscritas -presentadas como inmanentes e inmutables- a la masculinidad. En el material analizado las mujeres carecen de agencia y son mostradas desprovistas de cualquier característica que las defina como seres con voluntad propia, adoptando una posición de objeto (Lee Bartky, 1990), que a modo de trofeos (Royo, 2018) influyen en una autoestima masculina sujeta al acceso al cuerpo de las mujeres. Por lo tanto, las mujeres se convierten en lo que los hombres- en nuestro caso los «hombres ganadores»- no son, en el entramado occidental del dualismo masculino/femenino (Coral-Díaz, 2010). En este caso se convierten en «oveja» (presa), «cultivo», en inerte («huerto, pepita»), en lo pasivo, lo sumiso, sin capacidad de agencia, subordinadas a la actividad del hombre depredador o recolector:

Hay cazadores que acechan a sus presas para emboscarlas [...] pero tú no vas a ser uno de ellos. Tú vas a ir más allá, te vas a dejar de cacerías y te vas a convertir en un agricultor, te dedicarás a sembrar y a cuidar tu huerto (Luna, 2015, p. 111) [...] Cuando la hortaliza esté madura, recoléctala (Luna, 2015, p., 116) [...] Debes dejar de lado la pala por un momento y recoger la pepita [...]Recuerda, eres un lobo. Enséñale los dientes a la oveja (Luna, 2015, p., 119) [...] Cuando no están escalando con una mujer concreta, mejorando su vida o disfrutando de una de sus pasiones de Ganador, los encontrarás cuidando de sus cultivos. Han logrado sacar adelante un huerto fértil y próspero (Luna, 2015, p. 122)

\section{d. Riesgo y Virilidad}

Corresponde a los hombres realizar todos los actos a la vez breves, peligrosos y espectaculares que marcan unas rupturas en el curso normal de la vida (Bourdieu, 2000). Muchos hombres adoptan actitudes que cuestionan la seguridad y se basan en conductas de riesgo y demostraciones de valor, como una confirmación de su virilidad y valía como hombres (Emakunde, 2008). El privilegio masculino encuentra su contrapartida en la tensión y la contención permanentes, a veces llevadas al absurdo, que impone a cada hombre la tarea de afirmar su virilidad en cualquier circunstancia. La masculinidad es algo que está en constante (auto) evaluación (Ocampo, 2019). Virilidad entendida por un lado como la capacidad sexual, reproductiva y social y, por otro lado, también como aptitud para el combate y para el ejercicio de la violencia (Bourdieu, 2000). Si traemos a colación la importancia de las prácticas sexuales en la conformación de la identidad masculina para los hombres, y a ello le añadimos -como muestra Baker (2013) sobre los hombres que participan en comunidades de seducción- el considerar a las mujeres como un grupo homogéneo sexualizado, pasivo y subordinado ante el cual se debe insistir porque «un rechazo no es una opción», se generan violencias que se reproducen como invisibles, inocuas o incluso humorísticas pero que generan sufrimiento (Marina 
Castañeda, 2007) y que como veremos a continuación posibilitan y promueven la violencia sexual hacia las mujeres:

Piérdele el miedo a la sangre. Hazte atrevido y osado. Recréate en la tensión sexual y en los altibajos emocionales. Disfruta desconcertando, provocando, contradiciendo, decepcionando y violentando. Aprende a morder sin miedo y a desatar tu instinto animal. Hazlo como sea. Paga el precio (Luna, 2015, p. 118) (...) si eres valiente, atrevido, intrépido, osado, fresco, cara dura, audaz o temerario a la hora de acercarte a ella, mostrarle tu interés sexual ¿sabes lo que pasa? Sus genes le van a gritar «Nena, si tienes que montártelo con alguien que sea con este» Este interruptor sexual está tan arraigado en su sistema biológico que, aun cuando todos los hombres fuesen osados, el atrevimiento seguirá resultando atractivo para las mujeres (Luna, 2015, p. 126). Los psicólogos evolucionistas te lo dirán: a esa vecinita tuya le ponen los intrépidos. Especialmente cuando esté ovulando [...] Decenas de estudios psicológicos nos confirman, una y otra vez, que los amantes del riesgo les excitan (Luna, 2015, p.124) Tienes que demostrarle que eres el hombre de su vida. Debes dejarle claro que tú vas a darle acción sin que ella te lo pida (Luna, 2015, p. 113) Pero aún hay más razones para escalar. ¿Quieres que te dé la más potente de todas? Allá va: a las mujeres les excitan los osados. (Luna, 2015, p. 124)

\section{e. Protección y Presencia}

Bourdieu (2000) sostiene que las construcciones sobre masculinidad y feminidad se escriben sobre el cuerpo que, de alguna manera, está relacionado con la forma como se ha propuesto el uso de la fuerza. Un ejemplo de ello sería hablar de la fuerza superior de la masculinidad, frente a la fragilidad física y emocional femenina. De este modo, la masculinidad se caracteriza por una necesidad de dominar, y la manera más antigua de lograrlo es mediante la fuerza (Perry, 2017). Los hombres reafirman su masculinidad al ocupar con su cuerpo el espacio público, como si la feminidad se resumiera en el arte de empequeñecerse (Bourdieu, 2000). Como apunta Connell (1995), el género masculino se expresa como forma de sentir en la piel, ciertas formas y tensiones musculares, ciertas posturas y formas de moverse, ciertas posibilidades en el sexo; un cuerpo de un «hombre» de verdad, debe mostrar atributos como la fuerza, cierta complexión y tono muscular, posturas y movimientos (Salvador Cruz, 2006). Este apartado trae a colación las palabras del sociólogo Hugo Beigel (1951) cuando se refiere al amor cortés y a la galantería como un paliativo y un disfraz de la injusticia inherente a la posición social de la mujer. No es verdad que los hombres respeten a las mujeres: se respetan unos a otros a través de sus mujeres -esposas, amantes, entretenidas-; cuando la protección masculina deja de extenderse sobre ella, la mujer se encuentra desarmada ante una casta superior que se muestra agresiva, sarcástica u hostil (De Beauvoir, 1949). Ya a finales del siglo XIX la poetisa Aurelia Castillo hacía referencia a la posición de perpetua protegida de la mujer, de posición humillante que deja ancho campo a todos los abusos y cuyo resultado final e ineluctable es la postración de la voluntad (Valdés, 2007): 
Tócala. Cada minuto que pases sin tocarla, más sólida e infranqueable se vuelve la intangible barrera que os separan. Tu forma de tocarla debe ser firme, protectora y arropadora. Así se sentirá más segura. Por eso, tócala. Y tócala bien. (Luna, 2015, p.67) Al tocarla le estas dando algo valioso [...] tu actitud no es la del típico aprovechado, sino la de un cálido ganador que protege y cuida de quienes le rodean. Cuando toques haz que los demás se sientan arropados [...] y recuerda: nadie rechaza algo agradable, las chicas menos. (Luna, 2015, p.69) [...] ellas perciben en ti una energía firme $\boldsymbol{e}$ inamovible, pero a la vez, toneladas de cariño protector

\section{f. Racionalidad e Insensibilidad}

Hace ya más de dos siglos Mary Wollstonecraft (1792) condenaba la educación que se daba a las mujeres, pues las hacía «más artificiales y débiles de carácter de lo que de otra forma podrían haber sido» y porque deformaba sus valores con «nociones equivocadas de la excelencia femenina». Siguiendo en la línea de la educación diferencial, John Stuart Mill (1869) sostenía que a la mujer se le daba una educación de los sentimientos y no del entendimiento. Los hombres se identificaron a sí mismos con un lado de los dualismos: con lo racional, el pensamiento, la razón, lo objetivo... Las mujeres resultaron proyectadas hacia el otro lado e identificadas con lo irracional, el sentimiento, la emoción, lo subjetivo, lo concreto... (Olsen, 2000). Sánchez-Sicilia y Cubells (2018) observan cómo el discurso de la racionalidad y la objetividad en las relaciones afectivo-sexuales corresponde generalmente a los hombres y, por tanto, en el ámbito social, el amor va en detrimento de lo que se considera viril y masculino (Royo, 2018). Los hombres reciben una escasa o nula educación emocional, lo cual no quiere decir que no se les permitía mostrar sus sentimientos o emociones en público, sino que se muestra rechazo social generalizado a que los hombres muestren emociones que se han categorizado como femeninas: vulnerabilidad, debilidad, frustración... no aquellas que se categorizan como masculinas: la rabia, la ira, la lujuria... (Azpiazu, 2017). Por tanto, no estaríamos hablando de que los hombres no pueden mostrar emociones, sino que hay una serie de emociones permitidas y reforzadas y otras indeseables en la construcción del modelo de masculinidad tradicional.

Las mujeres nos ven a través de sus propias emociones [...]no se trata, pues, de que les hagas llegar un concepto. Se trata de que le hagas experimentar un sentimiento o emoción. Recuerda que cuando trates con mujeres, ya no necesitas ser objetivo. Sé específico y concreto. Y tan sensorial como puedas (Luna, 2015, p.90) La mayoría de los hombres presos de la lógica, tendemos a centrarnos únicamente en lo textual y para colmo prestamos demasiada atención a los razonamientos olvidando las emociones que hay detrás (Luna, 2015, p.103) La lógica retroactiva se trata de un principio básico de la psicología femenina. Céntrate en detectar sus emociones [...] Observa su estado, no sus palabras. Y no le des lo que estas piden. Dale, en cambio lo que necesita para que la relación prospere. (Luna, 2015, p.139) [...] Paralelamente desarrollará un miedo justificado a que, si no juega bien sus cartas, otra puede levantarle a su príncipe. No se lo impidas. (Luna, 2015, p. 75) 


\section{4.-Conclusiones}

El material que hemos analizado proporciona una serie de pautas sexo-afectivas y de seducción dirigidas a los hombres heterosexuales. Estas pautas construyen, reproducen y glorifican una serie de mandatos de la masculinidad, a la vez que se produce un efecto de socialización de lo biológico y de biologización de un fenómeno que en este trabajo hemos comprendido como dependiente de un contexto sociohistórico-cultural concreto y, por tanto, atravesado por condicionantes psicosociales que construyen un modelo deseable de masculinidad en detrimento de otros.

De este modo, este manual de seducción construye y promueve las siguientes características como deseables en los hombres: La virilidad sexual, entendida como el deber y la necesidad de mantener numerosas relaciones sexuales heterosexuales, donde los deseos sexuales de los hombres son priorizados sobre los de las mujeres; El poder y la dominación, necesidad de dominar, impresionar, evidenciar la presencia de poder y autoridad en las interacciones sexoafectivas; La actividad y la agencia, tomar como hombre el rol dominante y activo en detrimento de la voluntad de las mujeres, las cuales quedan supeditadas al (des)hacer de aquellos que dominan la interacción sexoafectiva; El riesgo asociado a la virilidad, donde el rechazo no es una opción y se debe hacer lo que sea necesario - sin problematizar las consecuencias derivadas de sus actos- para lograr el objetivo de mantener relaciones sexuales con las mujeres; La protección y la presencia, ser una figura que destaca a través de la expresión corporal y que transmite la sensación de proporcionar protección y cuidado a las mujeres; y por último, la racionalidad y la insensibilidad, es decir, actuar de forma premeditada y calculada en las interacciones sexo afectivas, rechazando el mostrar sentimientos o emociones socialmente consideradas «femeninas». Por tanto, podemos concluir que el modelo de masculinidad que se reproduce en este material constituye su identidad a partir de la virilidad, la actividad sexual, el poder, la dominación, la autoridad, la actividad, la agencia, el riesgo, la presencia, la protección, la insensibilidad y la racionalidad. Asimismo, invalidan cualquier otra posibilidad de «ser hombre» que no encaje o se identifique con este modelo o que no reproduzca esos mandatos de género $y$, a pesar de que estos hombres en el material son mayormente invisibilizados, cuando se hace referencia a ellos, son ridiculizados, infantilizados y tratados de forma despectiva.

A las mujeres a lo largo del material se las reduce y presenta como grupo homogéneo que a modo de objetos sexualizados logran representar y dotar de masculinidad a los hombres. El papel que juegan en las prácticas de seducción aquí presentadas es el de validar y reforzar la virilidad de los hombres. Por tanto, se convierten en lo que los hombres no son, se las presenta sin agencia, manipulables, dominadas, sin autoridad, pasivas, en segundo plano, necesitadas de cuidado, sensibles, emocionales... En definitiva, cuerpos sobre los que ejercer la dominación masculina. Por tanto, se promueve y hace posible el surgimiento de la violencia sexual hacia las mujeres en sus diversas formas.

A lo largo de todo material, de forma transversal emergen las teorías biologicistas y evolucionistas, como marco teórico en el que el autor se escuda para justificar sus 
pautas. De este modo, considera la existencia de una diferenciación sexual entre hombres y mujeres programada genéticamente, que determina sus pautas sexo afectivas y de seducción. El autor, mediante el empleo de estos enfoques, normaliza y justifica las pautas de seducción que presenta en sus libros, y rechaza e invisibiliza las diversas maneras de vivir la masculinidad, la feminidad, las interacciones sexoafectivas, y niega las posibilidades de modificación y transformación de estas pautas de seducción al no poner el foco sobre los agentes socializadores-entre los cuales se encuentra este manual- que construyen y reproducen un discurso sobre unas prácticas y comportamientos sexualmente diferenciados que consideran inmanentes e inmutables.

De este modo, en este trabajo no estamos invalidando los presupuestos biologicistas y evolucionistas como posibles variables explicativas de las diferencias sexuales en las pautas de seducción. Lo que hemos pretendido es realizar un abordaje a un fenómeno que consideramos dependiente y atravesado por un contexto socio-histórico-cultural concreto y cuyas variables explicativas no pueden caer en un reduccionismo fenomenológico centrado en teorías biologicistas que han sido puestas en discusión en infinidad de ocasiones. Asimismo, consideramos necesario traer a colación que el que una conducta responda a una predisposición genética o influencia biológica no significa que sea social o éticamente justificable.

Para finalizar, consideramos necesario remarcar que la masculinidad es un fenómeno relacional condicionado igualmente a un contexto socio-históricocultural determinado y, por ello, destacamos la necesidad de repensar y (auto) cuestionar los mandatos construidos de la masculinidad tradicional que se nos han impuesto y las consecuencias derivadas de estos mandatos para mujeres, otros hombres y los propios cuerpos y mentes de los hombres en los cuales se inscriben.

\section{5.-Bibliografía}

Amazon.es (2020). Los más vendidos de Amazon: Los más vendidos en guías sexuales. AmazonEspaña.www.amazon.es.https://www.amazon.es/gp/ bestsellers/books/13440917031/ref=pd_zg_hrsr_books_1_3_last

Amurrio Velez, Mila et al. (2010). «Violencia de género en las relaciones de pareja de adolescentes y jóvenes en Bilbao». Zerbitzuan, 47, 121-134

AzPIAzU, Jokin (2017). Masculinidades y Feminismo. Barcelona:Virus

BADINTER, Elisabeth. (1992). XY: De l'identité masculine. Odile Jacob

BAKER, Katie J.M. (2013). «Cockblocked by Redistribution: A Pick-Up Artist in Denmark». Dissent, vol 60, núm 2.

BARTKY, Sandra Lee (1990). Femininity and domination: Studies in the phenomenology of oppression. Psychology Press. https:/ / doi.org/10.4324/9780203825259

Birdwhistell, Ray, Desmonts, Antonio, \& Ramió, Joaquín (1979). El lenguaje de la expresión corporal. Barcelona: Gustavo Gili.

Bourdieu, Pierre (2000). Masculine domination. Stanford University Press.

BEACH, Frank, \& JoRdAN, Lisbeth (1956). «Sexual exhaustion and recovery in the male rat». Quarterly Journal of Experimental Psychology, 8(3), 121-133. 
Beigel, Hugo (1951). Romantic love. American Sociological Review, 16(3), 326-334. Buchbinder, David (2013). Studying men and masculinities. Abingdon:Routledge. CAstañedA, Marina (2007), El machismo invisible regresa, Taurus: México.

Сово, Rosa (2017). La prostitución en el corazón del capitalismo. Madrid: La Catarata. Connell, Raewyn (1995). Masculinities. Cambridge, UK: Polity Press.

Coral-Díaz, Ana Milena (2010). «El cuerpo femenino sexualizado: entre las construcciones de género y la Ley de Justicia y Paz». International Law 17: 381-409

Cruz, Salvador (2006). «Cuerpo, masculinidad y jóvenes». Iberoforum. Revista de Ciencias Sociales de la Universidad Iberoamericana, 1(1). Ciudad de México: Universidad Iberoamericana

De Beauvoir, Simone. (1949/1969). El segundo sexo. Buenos Aires: Siglo Veinte.

De Miguel, Ana (2015). Neoliberalismo Sexual: El mito de la libre elección. Madrid: Feminismos

Eibl-Eibesfeldt, Irenaus (1993). Biología del comportamiento humano. Manual de etología humana, Madrid: Alianza Editorial

ElboJ, Carmen, Flecha, Ainhoa, y Í̃̃̃guez, Tatiana (2009). «Modelos de atracción y elección de la población adolescente y su relación con la violencia de género. Propuesta para su prevención en base a los principios metodológicos de las comunidades de aprendizaje». Contextos Educativos, 12, 95-114

EMAKUNDE (2008). Los hombres, la igualdad y las nuevas masculinidades. Instituto Vasco de la Mujer

España (2006). «Real decreto legislativo 1/1996, de 12 de abril, por el que se aprueba el Texto refundido de la Ley de propiedad intelectual, regularizando, aclarando y armonizando las disposiciones legales vigentes sobre la materia». Boletín Oficial del Estado. Madrid, 22 de abril de 1996, núm. 97. https://www. boe.es/buscar/act.php?id=BOE-A-1996-8930

FigueroA-PereA, Juan Guillermo (1998) «Algunos elementos para interpretar la presencia de los varones en los procesos de salud reproductiva». Cad Sáude Pub 14(Suppl 1):87-96

FERrer, Victoria, y Bosch, Esperanza (2013). «Del amor romántico a la violencia de género. Para una coeducación emocional en la agenda educativa». Profesorado, $17,105-122$.

FisHer, Helen (1994). Anatomía del amor. Barcelona: Anagrama.

GERGEN, Kenneth (2007). Constructivismo social: aportes para el debate y la práctica. Universidad de los Andes, Facultad de Ciencias Sociales.

Gergen, Kenneth y Gergen, Mary (2011). Reflexiones sobre la construcción social. Paidós.

GLASER, Barney, \& STRAuss, Anselm (1967). The discovery of grounded theory. London: Weidenfeld and Nicholson, 24(25), 288-304.

GuAsch, Oscar (2008). «Homosexualidad, masculinidades e identidad gay en la tardomodernidad: el caso español». Mientras Tanto, (107), 27-47.

Hall, Jeffrey, \& CANTERberry, Melanie (2011). "Sexism and assertive courtship strategies». Sex Roles, 65(11-12), 840-853.

Hirschman, Elizabeth C. \& Thompson, Craig (1997). «Why media matter: Toward 
a richer understanding of consumers' relationships with advertising and mass media» Journal of Advertising, 26(1), 43-60.

IÑIGUEZ, Lupicinio (2008). El debate sobre metodología cualitativa versus cuantitativa. Material preparado para la Maestría en Ciencias Sociales. Universidad de Guadalajara. Guadalajara

KaUfman, Michael (1994). «Men, feminism, and men's contradictory experiences of power» Theorizing masculinities, 5, 142.Guadalajara: Guadalajara.

Kimmel, Michael (2017). Angry White men: American masculinity at the end of an era. New York, NY: Nation Books.

López-SÁez, Miguel Ángel; García-Dauder, Dau \& Montero, Ignacio (2019). El sexismo como constructo en psicología: una revisión de teorías e instrumentos. Quaderns de Psicologia, 21(3), e1523. http://dx.doi.org/10.5565/rev/ qpsicologia.1523

Lorenz, Konrad (1986). Fundamentos de la etología: estudio comparado de las conductas. Barcelona: Paidós

LunA, Mario (2011). SexCode. Madrid: Nowtilus

LunA, Mario (2013). SexCrack. Madrid: Espasa Libros

LunA, Mario (2015). ApocalipSex: Los 10 mandamientos de la seducción. Madrid: Espasa Libros.

MArqués, Vicent y Osborne, Raquel (1991). Sexualidad y sexismo, Madrid: UNED, Fundación Universidad-Empresa.

Millett, Kate (1970). Sexual politics. Columbia University Press.

Morris, Desmond (1980). El hombre al desnudo. Barcelona

Murillo, Javier et al. (2011). Teoría fundamentada o grounded theory. Universidad Autónoma de Madrid

OсAмpo, Ismael (2019). «¿Yo, hombre? Las masculinidades y el ser hombre en un programa reeducativo contra la violencia en México». Asparkía: Investigació feminista, (35), 67-86.

OlsEN, Frances (2000). «El sexo del derecho». En Ruiz, Alicia y Amorós, Celia (Eds.). Identidad femenina y discurso jurídico. Buenos Aires: Biblos

O'NeILl, Rachel (2018). Seduction: Men, Masculinity and Mediated Intimacy, MA: Polity.

PAdrós, María, Aubert, Adriana, y Melgar, Patricia (2010). «Modelos de atracción de los adolescentes. Contribuciones desde la socialización preventiva de la violencia de género». Revista Interuniversitaria de Pedagogía Social, 1723(17), 73-82

Perry, Grayson (2017). The Descent of Man. New York, NY: Penguin Books.

Rincón Aponte, Jeanette. (2014). «Estudio de los roles de seducción según género en jóvenes universitarios entre los 17 y 28 años en Bogotá». Mora (Buenos Aires), 20(2), 00-00.

Romero Díaz, Alfonso, \& Abril Morales, Paco (2011). «Masculinidades y usos del tiempo: Hegemonía, negociación y resistencia». Prisma Social, (7).

Royo, Adriana (2018). Falos y Falacias. Barcelona: Arpa.

SAMBADE, Iván (2017), «La instrumentalización de la sexualidad. Masculinidad patriarcal, pornografía y prostitución», en DE Miguel, Ana y NuÑo, Laura, 
Elementos para una teoría crítica del sistema prostitucional, Editorial Comares, Granada, 2017, pp. 169-180.

SÁnchez-SiciliA, Alejandro y Cubells, Jenny (2018). «Amor, Posmodernidad y perspectiva de género: Entre el amor romántico y el amor líquido», en Investigaciones feministas 9.1, 151-171. https:/ / doi.org/10.5209/INFE.58143

SCHEFLEN, Albert, \& SCHEFlen, Alice (1976). El lenguaje del cuerpo y el orden social: la comunicación como control de comportamiento. Diana:México.

Smart, Carol (2000). «La teoría feminista y el discurso jurídico». Biblos 31-71.

Strauss, Neil (2005) The game: Penetrating the Secret Society of Pickup Artists. EEUU: Regan Books

STOLLER, Robert (1994). Sex and gender: The development of masculinity and femininity. Karnac Books.

StUART Mill, John (1869). The subjection of Women. London

SubiRAts, Marina (2013). Forjar un hombre, moldear a una mujer. Barcelona: Aresta

Trivers, Robert (1972). Parental investment and sexual selection (Vol. 136, p. 179).

Cambridge, MA: Biological Laboratories, Harvard University.

VALdÉs, Mercedes (2007): Aurelia Castillo: ética y feminismo. Centro Félix Varela:La Habana.

Van Valkenburgh, Shawn (2018). «Digesting the Red Pill: Masculinity and Neoliberalism in the Manosphere». Men and Masculinities, Estados Unidos: The State University of New York

Wollstonecraft, Mary (1792). A Vindication of the Rights of Woman: with Strictures on Political and Moral Subjects. Boston

Yela, Carlos (2000). El amor desde la psicología social. Ni tan libres ni tan racionales. Madrid: Ediciones pirámide.

Recibido el 24 de abril de 2020 Aceptado el 9 de septiembre de 2020 BIBLID [1132-8231 (2020): 115-132] 